

\title{
Method for Estimating Quantity of Non-Hydrated Cement in a Cement Recycling System
}

\author{
Daiki Atarashi $^{{ }^{*}}$, Tetsuji $\mathrm{Kamio}^{2}$, Yutaka Aikawa ${ }^{3}$, Masahiro Miyauchi ${ }^{4}$ and Etsuo Sakai ${ }^{5}$
}

\begin{abstract}
The objective of this research was to develop a method for the rapid estimation of the quantity of residual cement in sludge water and to control its hydration reaction using sodium gluconate in order to enable the residual cement in sludge water to be effectively utilized. The quantity of residual cement in sludge water can be estimated by measuring the heat of hydration liberated in $24 \mathrm{~h}$ using a conduction calorimeter. It is possible to recommence sodium gluconate-controlled cement hydration using magnesium nitrate. A method was developed to simulate the rate of the hydration reaction, which makes it possible to estimate the quantity of residual cement in sludge water by measuring the rate of heat liberation of hydration over $10 \mathrm{~h}$.
\end{abstract}

\section{Introduction}

In today's society, where there is a need to implement low carbon recycling systems, the reduction and reuse of waste sludge water from the production of ready-mixed concrete at factories is an important issue. Data from 2006 indicate that about 1 million tons of sludge are generated annually in Japan.

Sludge is a mixture of cement and very fine aggregate that occurs as waste at construction sites or forms when residual recycled concrete is sieved to remove aggregates. Cleaning water that contains a sludge component, which is referred to as sludge water, is formed when water is used to clean equipment such as ready-mixed-concrete mixers and agitators.

To reduce the quantity of sludge formation at ready-mixed-concrete factories, Japanese Industrial Standard A 5308 "Ready-mixed Concrete" prescribes a method of using mortar that adheres to the inside of truck agitator drums. This allows for a solid sludge component of up to $3 \%$ (the mass of the solid sludge component as a percentage of the unit cement quantity in the concrete mix) to exist in sludge water when it is used as concrete

\footnotetext{
${ }^{1}$ Assistant Professor, Tokyo Institute of Technology, Graduate School of Science and Engineering, Tokyo, Japan. *Corresponding author,

E-mail: datarashi@ceram.titech.ac.jp

${ }^{2}$ Master course student, Tokyo Institute of Technology, Graduate School of Science and Engineering, Tokyo, Japan.

${ }^{3}$ Researcher, Tokyo Institute of Technology, Graduate School of Science and Engineering, Tokyo, Japan.

${ }^{4}$ Associate Professor, Tokyo Institute of Technology, Graduate School of Science and Engineering, Tokyo, Japan.

${ }^{5}$ Professor, Tokyo Institute of Technology, Graduate School of Science and Engineering, Tokyo, Japan.
}

mixing water. However, if sludge water is added, the concrete fluidity is reduced and the quantity of water required to produce the concrete increases. This method is not used widely because of its high cost and complicated management of sludge water. The number of ready-mixed-concrete factories that use sludge water as concrete mixing water is low and the amount of industrial waste that they generate after the dewatering process is large.

Sludge water contains fine particles that originate from cement that has already been hydrated, and from non-hydrated cement and aggregates. By using a set retarder such as sodium gluconate (GLNa) or similar, the hydration reaction of the unhydrated cement in the sludge water can be controlled (Atarashi et al. 2012a). The sludge water can then be reused effectively to replace a portion of the new cement when producing ready-mixed concrete. This could reduce the required cement production quantity, which would contribute significantly to reductions in $\mathrm{CO} 2$ emissions.

It is necessary to establish a method to determine the amount of non-hydrated cement in the sludge water so that this non-hydrated cement can be used as cement. To date, the authors have found that there is a correlation between the percentage of reacted alite, which contributes to the generation of early strength in cement, and the liberated heat of hydration as obtained from a conduction calorimeter (Atarashi et al. 2012b). A prototype conduction calorimeter that is capable of measuring the heat of hydration of cement has been produced jointly with Tokyo Riko, a calorimeter-manufacturing company (Sakai et al. 1997). It is suggested that the measurement of heat using a calorimeter can be utilized effectively in cement quality control and inspection (Sakai et al. 2010).

The objective of this research was to formulate a method for the rapid evaluation of the quantity of cement remaining in sludge water whose hydration reaction has been suppressed using GLNa. This could enable the effective reuse of residual cement in sludge water. In the 
method, the amount of non-reacted cement remaining in the sludge water is determined using a conduction calorimeter. Furthermore, a method for the rapid evaluation of the quantity of non-reacted cement in sludge water, for which the hydration has been suppressed, was developed using a metallic salt and computer simulation. The objective was to integrate these research results to establish a new cement recycling system to use the cement contained in sludge water effectively.

\section{Test outline}

\subsection{Test materials}

The cement used in this study was ordinary Portland cement (OPC) with the properties listed in Tables $\mathbf{1}$ and 2. The chemical composition of OPC was measured in accordance with JIS R5204, and the mineral composition of OPC was calculated from the chemical composition using Bogue's equation. GLNa was used as the set retarder, and magnesium nitrate hexahydrate $\left(\mathrm{Mg}\left(\mathrm{NO}_{3}\right)_{2} \cdot 6 \mathrm{H}_{2} \mathrm{O}\right)$, which has an accelerating effect on the retarded cement, was used as the metallic salt (Harada 1995,1996$)$.

\subsection{Determining the residual quantity of cement in sludge water}

Simulated sludge was produced with a water cement ratio $(\mathrm{W} / \mathrm{C})$ of 4.0 without the addition of GLNa and $\mathrm{Mg}\left(\mathrm{NO}_{3}\right)_{2} \cdot 6 \mathrm{H}_{2} \mathrm{O}$. It was mixed manually for $3 \mathrm{~min}$ at $20^{\circ} \mathrm{C}$. After allowing the hydration reaction to proceed for 1 to $24 \mathrm{~h}$ at $20^{\circ} \mathrm{C}$, the hydration was stopped with a large amount of acetone, and the quantity of residual cement $\left(\mathrm{C}_{3} \mathrm{~S}\right)$ was determined by comparing the areas under the peaks at 51.78 (2theta) obtained from x-ray diffractometry (XRD). The effect of the amount of hydrates was canceled by using weight loss on ignition (Imoto et al. 2002).

Sample hydration was stopped with a large amount of acetone for samples that had been hydrated between 0 and $24 \mathrm{~h}$. After drying the acetone by aspirator, the hydration of this cement was recommenced for $24 \mathrm{~h}$ at $20^{\circ} \mathrm{C}$. The integrated quantity of the heat of hydration liberated from the cement paste was measured using a twin conduction calorimeter (Tokyo Riko, Tokyo, Japan). By comparing the XRD quantitative method and calorimetric data, the validity of the method for determining the quantity of residual alite in the residual cement was investigated.

\subsection{Rapid evaluation of the quantity of residual cement in sludge water using metallic salt and a conduction calorimeter}

The cement paste (produced using ordinary Portland cement for research purposes) had a W/C of 4.0, and a GLNa content of $0-0.2$ mass \%. Mixing was carried out manually for $3 \mathrm{~min}$ at $20^{\circ} \mathrm{C}$. GLNa was added after hydration for $1 \mathrm{~h}$ at $20^{\circ} \mathrm{C}$ to produce simulated sludge water in which the hydration was suppressed. Then, $\mathrm{Mg}\left(\mathrm{NO}_{3}\right)_{2} \cdot 6 \mathrm{H}_{2} \mathrm{O}$ was added at 0 to 8.0 mass $\%$ with respect to the cement, and the mixture was sampled. The heat of hydration properties of this simulated sludge water were determined using a conduction calorimeter.

\subsection{Liquid phase concentration of GLNa}

Centrifugal separation was carried out at 10,000 rpm (3400G) for $10 \mathrm{~min}$ on simulated sludge prepared in the same manner as described in Section 2.3. The supernatant water obtained was filtered using a membrane filter with $0.20 \mu \mathrm{m}$ diameter holes. The residual concentration of GLNa in the liquid phase was calculated using a total organic carbon analyzer (TOC5050A, Shimadzu, Kyoto, Japan).

\section{Test results and discussion}

\subsection{Development of method for determining the quantity of residual cement in sludge water using calorimetric measurement}

An investigation was carried out with the objective of establishing a method to determine quantitatively the amount of residual cement in sludge water using a conduction calorimeter.

Figure 1 shows the relationship between the quantity of residual cement $\left(\mathrm{C}_{3} \mathrm{~S}\right)$ in the sludge water and the cumulative heat of hydration liberated during the $24 \mathrm{~h}$ period after recommencing the hydration. The cumulative heat of hydration of the non-hydrated cement is expressed as a relative heat of hydration with the cumulative heat of hydration in $24 \mathrm{~h}$ being 100 .

As the quantity of residual cement in the sludge water increased, the relative heat of hydration in $24 \mathrm{~h}$ increased. However the regression curve does not cross the origin because of the background noise of the calorimetric data, a correlation was found between the quantity of residual cement $\left(\mathrm{C}_{3} \mathrm{~S}\right)$ in the sludge water and the cumulative heat of hydration liberated during the $24 \mathrm{~h}$ period after recommencing the hydration.

The conventional quantitative determination of the

Table 1 Chemical composition of ordinary Portland cement (mass\%) (Measured with JIS R5204).

\begin{tabular}{|c|c|c|c|c|c|c|c|c|c|}
\hline $\mathrm{SiO}_{2}$ & $\mathrm{Al}_{2} \mathrm{O}_{3}$ & $\mathrm{Fe}_{2} \mathrm{O}_{3}$ & $\mathrm{CaO}$ & $\mathrm{MgO}$ & $\mathrm{SO}_{3}$ & $\mathrm{Na}_{2} \mathrm{O}$ & $\mathrm{K}_{2} \mathrm{O}$ & Other & Total \\
\hline 21.56 & 4.68 & 2.98 & 65.63 & 1.30 & 1.90 & 0.33 & 0.39 & 1.23 & 100.00 \\
\hline
\end{tabular}

Table 2 Physical properties and mineral composition of ordinary Portland cement (mass\%) (Calculated with Bogue's equation).

\begin{tabular}{|c|c|c|c|c|c|c|}
\hline Density $\left(\mathrm{g} / \mathrm{cm}^{3}\right)$ & Blaine $\left(\mathrm{cm}^{2} / \mathrm{g}\right)$ & $\mathrm{C}_{3} \mathrm{~S}$ & $\mathrm{C}_{2} \mathrm{~S}$ & $\mathrm{C}_{3} \mathrm{~A}$ & $\mathrm{C}_{4} \mathrm{AF}$ & $\mathrm{CaSO}_{4} \cdot 2 \mathrm{H}_{2} \mathrm{O}$ \\
\hline 3.16 & 3310 & 62 & 15 & 7 & 9 & 3.2 \\
\hline
\end{tabular}


amount of non-hydrated cement remaining in cement must be measured using an XRD internal reference method, which requires skill in measurement and time. The measurement of the heat of hydration as proposed in this research enables the quantity of residual cement in sludge water to be estimated simply and in $24 \mathrm{~h}$.

\subsection{Investigation of rapid method to determine the quantity of cement in sludge water using magnesium nitrate}

If it were possible to estimate the quantity of residual cement in sludge water rapidly, it would be possible to use the cement in the sludge water occurring in ready-mixed-concrete factories effectively and this could reduce the environmental load.

Figure 2 shows the effect of $\mathrm{Mg}\left(\mathrm{NO}_{3}\right)_{2} \cdot 6 \mathrm{H}_{2} \mathrm{O}$ on the heat of hydration properties of sludge water to which GLNa has been added.

Time $\mathrm{T} 1$, which indicates the maximum rate of heat liberation of plain paste, is $11 \mathrm{~h}$ as shown by the dashed line on the graph. T1 for plain paste increases significantly with the addition of GLNa. As reported previously (Song et al. 2004, 2008), this occurs because GLNa is absorbed onto the cement surface, thereby suppressing hydration and making it possible to control the reaction of the cement by controlling the GLNa dosage. For example, when this dosage is 0.05 and 0.1 mass $\%$, T1 is 14 and $29 \mathrm{~h}$, respectively, and at 0.15 and 0.20 mass $\%$, T1 is more than $50 \mathrm{~h}$. With the addition of $\mathrm{Mg}\left(\mathrm{NO}_{3}\right)_{2} \cdot 6 \mathrm{H}_{2} \mathrm{O}, \mathrm{T} 1$ decreases as the dosage increases. For example, at a GLNa dosage of 0.1 mass $\%$, when 1.0 and 2.0 mass $\%$ $\mathrm{Mg}\left(\mathrm{NO}_{3}\right)_{2} \cdot 6 \mathrm{H}_{2} \mathrm{O}$ are added, $\mathrm{T} 1$ is 15 and $11 \mathrm{~h}$, respectively. The latter value is almost the same as the $\mathrm{T} 1$ value of the plain paste without the addition of GLNa and $\mathrm{Mg}\left(\mathrm{NO}_{3}\right)_{2} \cdot 6 \mathrm{H}_{2} \mathrm{O}$.

It has therefore been shown that by sampling a portion of sludge water in which hydration has been prevented by $\mathrm{GLNa}$ and $\mathrm{Mg}\left(\mathrm{NO}_{3}\right)_{2} \cdot 6 \mathrm{H}_{2} \mathrm{O}$ addition, it is possible to eliminate the suppression of cement hydration.

\subsection{Mechanism of recommencing hydration re- action using magnesium nitrate}

The mechanism for recommencing hydration using $\mathrm{Mg}\left(\mathrm{NO}_{3}\right)_{2} \cdot 6 \mathrm{H}_{2} \mathrm{O}$ was then investigated.

Figure 3 shows the specific surface area of the solid component of the sludge water and the concentration of GLNa in the liquid phase of the sludge water to which 0.1 mass $\% \mathrm{GLNa}$ and $\mathrm{Mg}\left(\mathrm{NO}_{3}\right)_{2} \cdot 6 \mathrm{H}_{2} \mathrm{O}$ at dosage of 0 to 4.0 mass $\%$ were added.

As the dosage of $\mathrm{Mg}\left(\mathrm{NO}_{3}\right)_{2} \cdot 6 \mathrm{H}_{2} \mathrm{O}$ increases, the concentration of GLNa in the liquid phase decreases rapidly, and the specific surface area of the solid component of the sludge water increases significantly. Also, when the dosage of $\mathrm{Mg}\left(\mathrm{NO}_{3}\right)_{2} \cdot 6 \mathrm{H}_{2} \mathrm{O}$ is 1.0 mass $\%$ or higher, the concentration of GLNa in the liquid phase and the specific surface area of the solid component of the sludge water become almost constant.

The authors have reported that the GLNa is in equi-

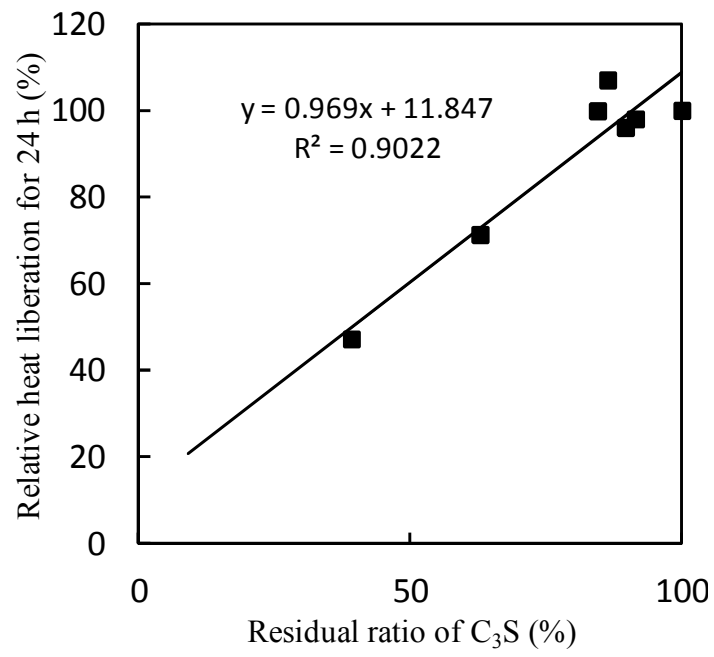

Fig. 1 Relationship between residual ratio of $\mathrm{C}_{3} \mathrm{~S}$ and relative heat liberation in $24 \mathrm{~h}$.

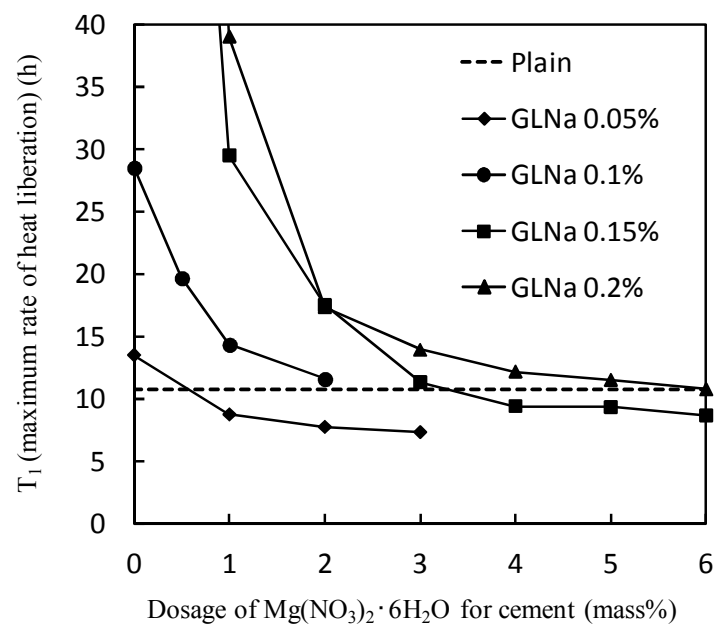

Fig. 2 Influence of $\mathrm{Mg}\left(\mathrm{NO}_{3}\right)_{2} \cdot 6 \mathrm{H}_{2} \mathrm{O}$ on T1.

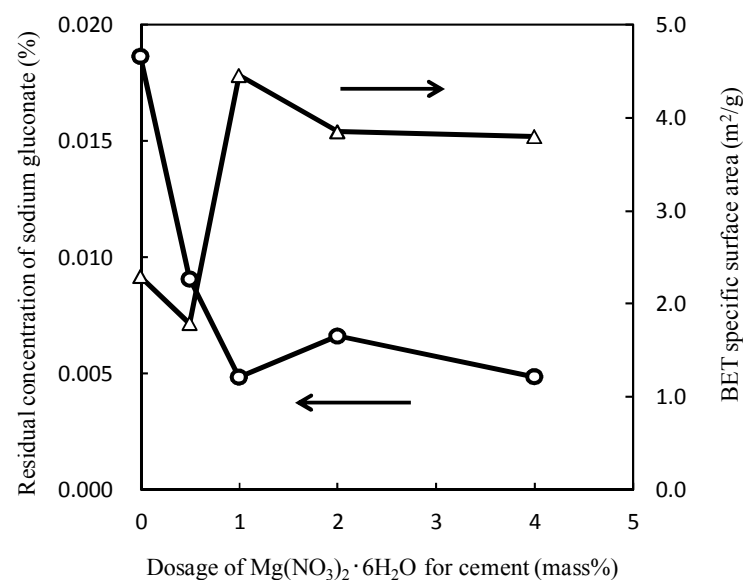

Fig. 3 Relationship between $\mathrm{Mg}\left(\mathrm{NO}_{3}\right)_{2} \cdot 6 \mathrm{H}_{2} \mathrm{O}$ dosage and residual concentration of GLNa.

librium Langmuir adsorption on the alite in the cement; that there is a correlation between the concentration in the liquid phase and T1; and as the concentration in the liquid phase decreases, T1 also decreases (Song et al. 


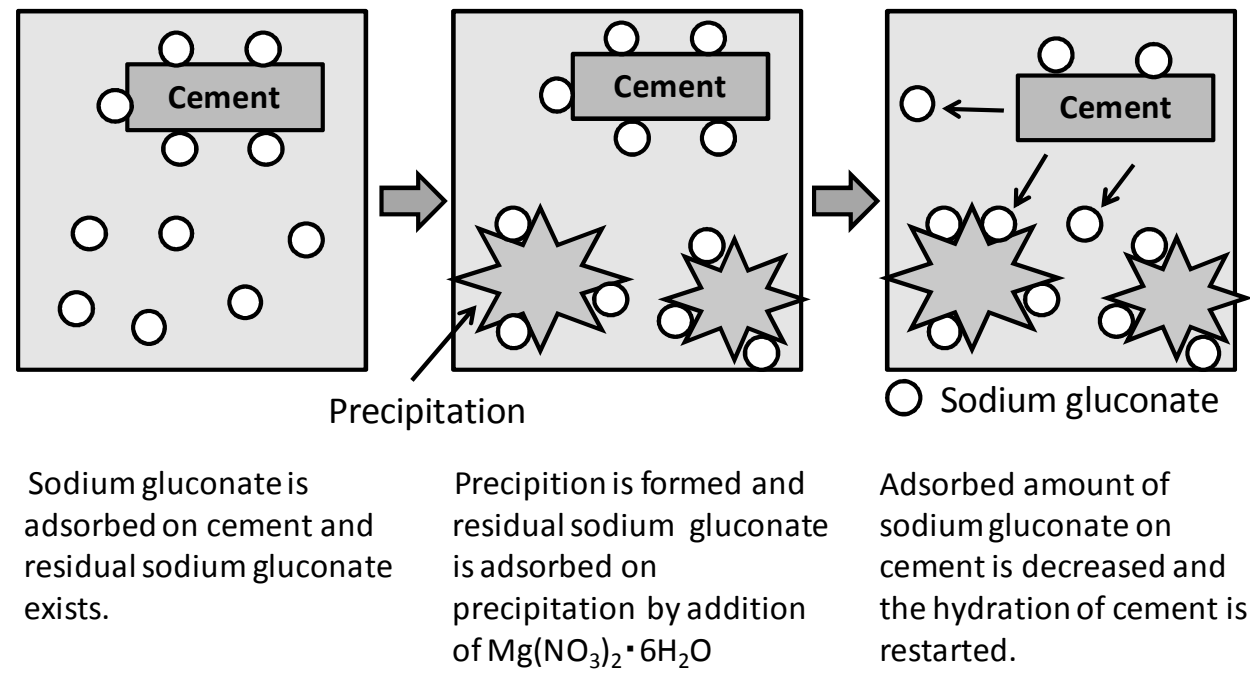

Fig. 4 Schematic illustration of $\mathrm{Mg}\left(\mathrm{NO}_{3}\right)_{2} \cdot 6 \mathrm{H}_{2} \mathrm{O}$ effect on retardation of cement hydration.

2008). From these results, the mechanism for recommencing hydration using $\mathrm{Mg}\left(\mathrm{NO}_{3}\right)_{2} \cdot 6 \mathrm{H}_{2} \mathrm{O}$ is assumed to be as shown schematically in Fig. 4.

Precipitation was caused by the addition of $\mathrm{Mg}\left(\mathrm{NO}_{3}\right)_{2} \cdot 6 \mathrm{H}_{2} \mathrm{O}$ so that the specific surface area of the solid component of the sludge water increases significantly, and the residual concentration of GLNa in the liquid phase is reduced accordingly. It is thought that the GLNa that is absorbed onto the alite in the cement is released as a result. The reduction in quantity of absorbed GLNa eliminates the hydration retardation affect, and as a result, hydration recommences.

\subsection{Development of a rapid method to estimate the residual cement by predicting the heat lib- eration curve}

A model that is capable of simulating all of the extremely complex compound reaction processes of hydration, including the initial reaction, the latent period, and the rate of heat liberation from the exothermic reaction until the end of the reaction, based on engineering knowledge, has been proposed by Tomosawa (1974). This model uses the following equation to represent the rate of the hydration reaction and the percentage completion:

$$
-\frac{\mathrm{d} \alpha}{\mathrm{d} t}=\frac{3 C_{w \infty}}{r_{0}^{2} v \rho_{C}} \frac{1}{\frac{1}{k_{d} \alpha^{2 / 3} r_{0}}+\frac{\alpha^{-1 / 3}-(2-\alpha)^{-1 / 3}}{D_{e}}+\frac{1}{k_{r} \alpha^{2 / 3} r_{0}} .}
$$

where $r_{0}$ is the radius of the unreacted cement particles in the initial period, $\rho_{c}$ is the density of the unreacted cement, $k_{r}$ is the coefficient of the rate of reaction at the reaction surface, $v$ is the stoichiometric proportion for the reaction between water and cement (mass standard), and $C_{\text {wo }}$ is the concentration of water at the surface of the hydration compounds.

It is assumed that the hydration compounds are double the volume of the unreacted cement. Mass transfer coefficient $k_{d}$ in the initial reaction stage and effective diffusion coefficient $D_{e}$ of water in the gel are expressed as functions of the percentage unreacted cement particles, as follows:

$$
\begin{aligned}
& k_{d}=\frac{B_{d}}{1-\alpha}+C_{d}(1-\alpha)^{2}, \\
& D_{e}=D_{E}\left(\ln \frac{1}{1-\alpha}\right)^{2}
\end{aligned}
$$

By carrying out a simulation of the rate of heat liberation from various types of Portland cement using Eq. (1), it is possible to determine each of the parameters.

By analyzing the amount of change of peak position of the rate of heat liberation by adding GLNa as shown in Fig. 5, the parameters of the Tomosawa model are simulated as shown by Table 3. It reveals that the delay of the reaction by adding GLNa is caused by decreasing mass transfer coefficient $k_{d}$. As a result, it is possible to simulate the quantity of additional material such as GLNa in accordance with the peak position.

As shown in Fig. 6, the quantity of residual cement in sludge water can be determined by sampling a portion of the sludge water whose hydration initiation time has been retarded by the addition of GLNa. The metallic salt

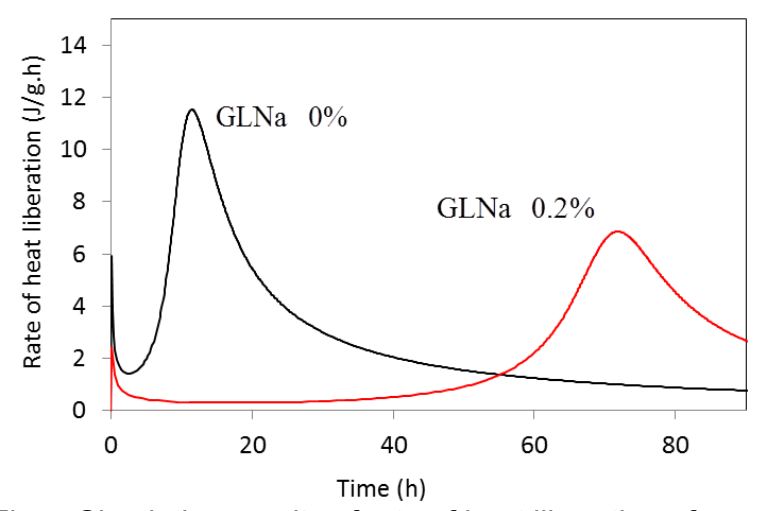

Fig. 5 Simulation results of rate of heat liberation of Portland cement that contains GLNa. 
$\mathrm{Mg}\left(\mathrm{NO}_{3}\right)_{2} \cdot 6 \mathrm{H}_{2} \mathrm{O}$ can then be added to obtain a test specimen in which the retarded hydration is restored to the original state, and the rate of heat liberation of hydration from this test specimen can be measured to evaluate the residual quantity of cement in the sludge water.

Approximately $50 \mathrm{~h}$ of measurement time are required to simulate this rate of heat liberation. However, by using the properties of the heat liberation curve derived from Eq. (1), it is possible to reduce the measurement time significantly. The process from the initial latent period to the accelerating period in the hydration reaction corresponds to the process from the curve to express a local minimum to the maximum peak in the rate of liberation. Experience has shown that if simulation is carried out up to this peak, the measurement values after the peak can also be described by the simulation. Therefore, by simulating the measurement values for $12 \mathrm{~h}$ up to the peak value of the rate of heat liberation, it is possible to predict the entire rate of heat liberation. The results are shown in Fig. 7.

The simulation can be carried out for the heat liberation curve using measurements in $10 \mathrm{~h}$, which is expected to reduce the evaluation time significantly. If it is possible to carry out such a rapid evaluation, then sludge water whose hydration has been suppressed the previous day can be used to produce concrete the following day.

\section{Conclusions}

The objective of this research was to develop a rapid method for evaluating the quantity of residual cement in sludge water whose hydration reaction has been retarded using GLNa, so that the residual cement contained in the sludge water can be used effectively. A method for determining the quantity of non-hydrated cement in the sludge water (whose hydration has been retarded using GLNa) has been developed using a conduction calorimeter or a computer simulation method. The results are as follows.

1) It is possible to estimate the quantity of residual cement in sludge water by measuring the quantity of heat liberated in $24 \mathrm{~h}$ using a conduction calorimeter.

2) A method to simulate the rate of the hydration reaction was developed. This method enables the quantity of residual cement in sludge water to be estimated by measuring the rate of heat liberation of hydration up to $10 \mathrm{~h}$.

As a result of this research, it is possible to effectively use sludge water that has been inadequately used in the past. Further, the possibility of reusing the cement component in sludge water effectively would allow the cement and concrete industry to increase the use of industrial waste and contribute to the development of a recycling and low carbon society. Therefore, the social and secondary effects of this research are significant.

Japanese cement industry $\mathrm{CO}_{2}$ emissions are large, next to those of the electrical power and iron and steel
Table 3 Fitting parameters in Eq.(1) simulated at GLNa $0 \%$ (Plane) and GLNa 0.2\%.

\begin{tabular}{|c|c|c|}
\hline & GLNa 0\% & GLNa 0.2\% \\
\hline$k_{r}[\mathrm{~cm} / \mathrm{h}]$ & $6.3 \times 10^{-6}$ & $5.0 \times 10^{-5}$ \\
\hline$B_{d}[\mathrm{~cm} / \mathrm{h}]$ & $3.0 \times 10^{-9}$ & $9.0 \times 10^{-10}$ \\
\hline$C_{d}[\mathrm{~cm} / \mathrm{h}]$ & $1.2 \times 10^{-3}$ & $1.0 \times 10^{-4}$ \\
\hline$D_{e}\left[\mathrm{~cm}^{2} / \mathrm{h}\right]$ & $1.0 \times 10^{-10}$ & $1.0 \times 10^{-10}$ \\
\hline
\end{tabular}

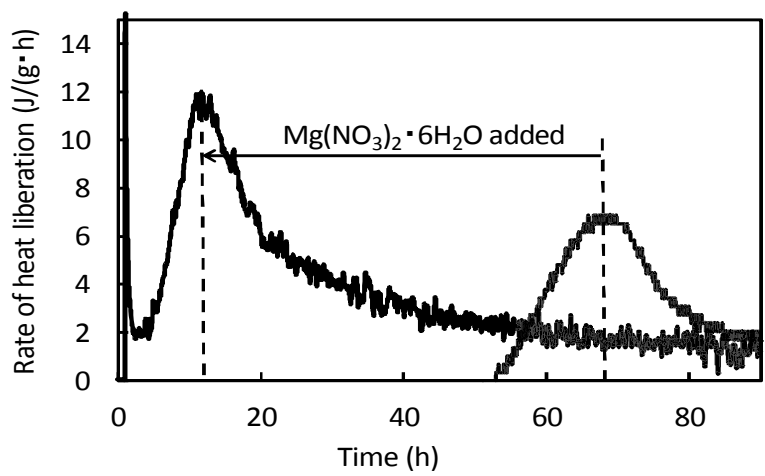

Fig. 6 Influence of $\mathrm{Mg}\left(\mathrm{NO}_{3}\right)_{2} \cdot 6 \mathrm{H}_{2} \mathrm{O}$ on cement hydration.

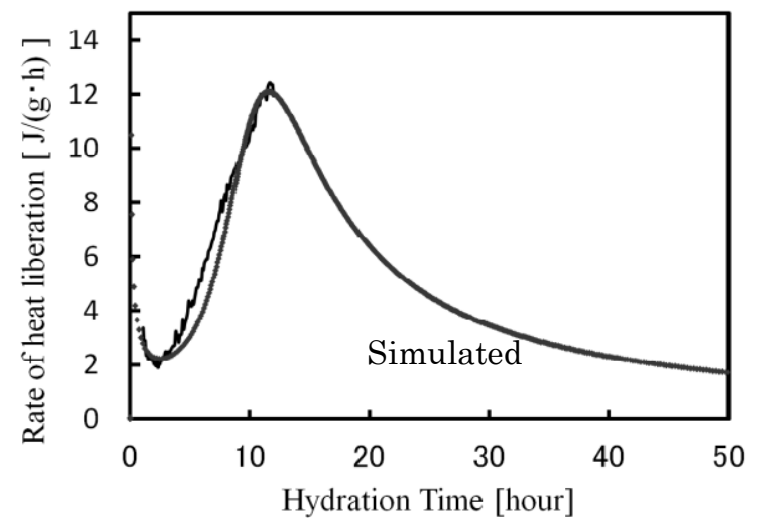

Fig. 7 Result of heat liberation curve by simulation method.

industries. The results from this research are expected to contribute to the achievement of Japan's $\mathrm{CO}_{2}$ emission targets by further reducing these emissions in cement production.

\section{Acknowledgment}

A portion of this research was carried out using 2012 and 2014 research grants from the Maeda Engineering Foundation, for which the authors express their gratitude.

\section{References}

Atarashi, D., Song, Y.-J., Nishimura, T. and Sakai, E., (2012 a). "Control of cement hydration by sodium gluconate in recycling system." The 10th CANMET/ACI International Conference Superplasticizers and other chemical admixtures in concrete Supplementary Papers, 197-208.

Atarashi, D., Yamada, M., Miyauchi, M. and Sakai, E., (2012 b). "Study on cement recycling system using sodium gluconate." Cement Science \& Concrete Technology, 66, 22-27. (in Japanese) 
Harada, H., Sotokawa, S. and Shirai, T., (1995). "The effect of metallic salts addition on the hydration restarting of retarded cement paste." Cement Science \& Concrete Technology, 49, 78-83. (in Japanese)

Harada, H., Shirai, T. and Sotokawa, S., (1996). "Hydration restarting mechanism of metallic salts added to retarded cement paste." Cement Science \& Concrete Technology, 50, 44-49. (in Japanese)

Imoto, H., Sakai, E. and Daimon, M., (2002). "Quantitative analysis for the hydration of limestone filler cement." Cement Science \& Concrete Technology, 56, 42-49. (in Japanese)

Sakai, E., Tsutsumi, K. and Daimon, M., (1997). "Measurement of cement hydration by means of sandwich type calorimeter." Cement Science \& Concrete Technology, 51, 68-71. (in Japanese)

Sakai, E., Maruya, E., Hagiwara, S. and Daimon, M.,
(2010). "Material design of cement for increased waste usage and quality control systems of cement by using of various types of calorimeter." Cement \& Concrete, 756, 48-52. (in Japanese)

Song, Y.-J., Sakai, E., Takeuchi, T. and Daimon, M., (2004). "Effect of set retarder on hydration and available time of sludge." Cement Science \& Concrete Technology, 58, 601-606. (in Japanese)

Song, Y.-J., Sakai, E., Takeuchi, T. and Daimon, M., (2008). "Control of cement hydration by sodium gluconate for recycling of the cement sludge." Cement Science \& Concrete Technology, 62, 530-537. (in Japanese)

Tomosawa, F., (1974). "Model of cement hydration reactions." Review of the General Meeting Technical Session of Cement Technology, 28, 53-57. (in Japanese) 